\title{
Performance of Internal Combustion Engine - A Review
}

\author{
Shahil Kumar \\ M. Tech \\ R.K.D.F Institute of Science and Technology \\ Bhopal (MP), India \\ kshahil300@gmail.com
}

\author{
Mr. Vishal Diwakar \\ Assistant Professor \\ R.K.D.F Institute of Science and Technology \\ Bhopal (MP), India \\ vishaldiwakar03@gmail.com
}

\begin{abstract}
To maintain a machine running, a variety of fuels are required. Millions around the world have continued to work on the Internal Combustion (IC) engine, its processes, and its development despite the passage of time. In recent years, the main focus has been on improving fuel economy and lowering emissions. There is no alternative type that provides significant fuel economy or controlled emission perks, and none that compares to today's engines in terms of overall ease, protection, and adaptability, according to researchers. Thus, in this paper, we are discussing combustion engines, their types, and how they work, as well as the work done by a number of researchers to improve the efficiency of heat exchangers in combustion engines of various geometries.
\end{abstract}

Keywords: Combustion Engine, Internal Combustion Engine, External Combustion Engines, Spark Ignition Engine, Gas Turbine Engine.

\section{INTRODUCTION}

Due to expanding stringent requirements for reduced fuel usage, combustion-engine technology has progressed tremendously in latest generations. As a result of these requirements, the quantity of engine sensors and devices has increased. At the very same moment, computers have grown at an exponentially, and computational resources has become more readily available. These developments have paved the way for more intellectual engine-control systems that can supervise the combustion procedure and modify actuators in real - time basis for reliable and sustainable combustion. Responsive low-emission combustion theories can be enabled by these control systems. Partially premixed burning is an ignition principle and have been shown to concurrently offer high efficiency and low emission levels. Its responsiveness to chemical reaction, on the other hand, has made it very difficult to use.

Transportation is required around the world to meet the most fundamental requirements in one way or another. From this point forward, the combustion engine is invisible. It takes a variety of fuels to keep a machine running. The people all around the world has been working on the Internal
Combustion (IC) engine, its processes, and its advancement from the past to the present. In recent years, the primary focus has been on improving fuel economy and lowering emissions. Researchers have discovered no alternative type that provides substantial fuel economy or controlled emission advantages, and those which not comes close to the overall easiness, protection, and adaptability of today's engines.Internal combustion (IC) engines are made up of several components, including the cylinder, cylinder head, piston, joining rod, valve process, crankshaft, and flywheel.

The operating fluid is filled inside the cylinder of heat engine and moves the piston. The gas charge is transferred to the crankshaft which is taken by the piston via the joining rod. The joining or connecting rod transform the piston stroke motion into crankshaft rotatory motion, and thus power is delivered from the shaft to the designated equipment. Figure 1 depicts the majority of the constituents of a reciprocating internal combustion engine.

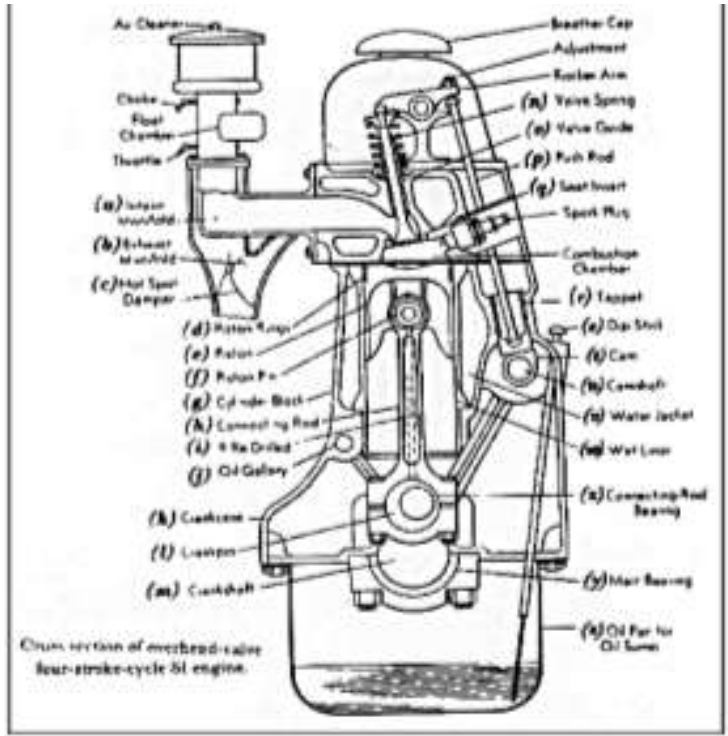

Figure 1Detailed Spark Ignition Engine Components

Almost every cylinder primarily consisted of two valves: the first is an intake or inlet valve, and the other is an exit or outlet valve [6]. The ignition system contains a battery, an 
induction coil, a supplier with cams and halt marks, and a sparking plug for each cylinder. Instead of an ignition system, diesel engines use an injector. We would not really go into detail about two- and four-stroke engines because these are basic concepts in combustion engines. Figure 2 depicts the components of the Ignition engine as we have discussed above.

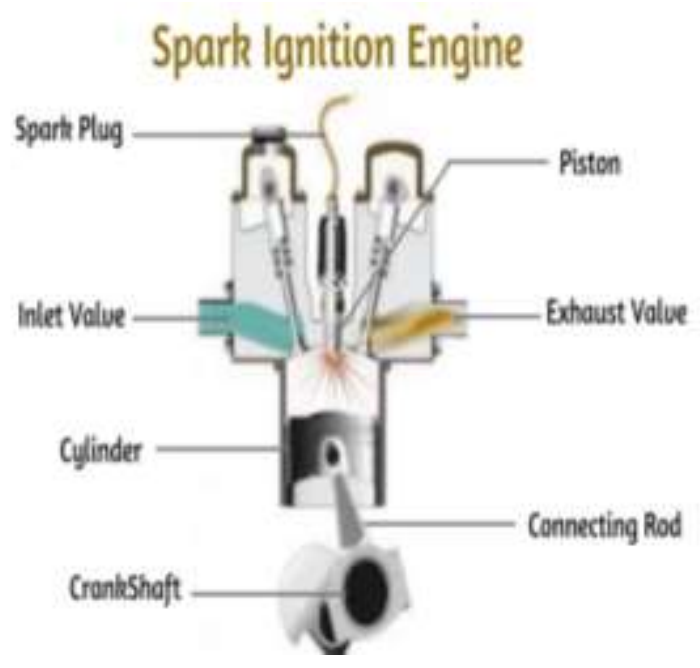

Figure 2 Schematic Diagram of Spark Ignition Engine

\section{A. INTERNAL COMBUSTION ENGINES}

An instrument that transforms the energy out of a fuel into heat energy and utilizes that heat energy to execute mechanical task is known as an engine. The term "heat engine" refers to engines that transform heat energy into execution of mechanical tasks. The most common type of heat engines are External combustion engines (EC Engines) as well as Internal combustion engines (IC engines) (IC Engines).

External Combustion engine - Fuel is burned extrinsically, or outside the engine, in defined as an external combustion engine. The heat energy released by burning of fuel is often used to raise the temperature of water and convert it to steam. A piston within a cylinder is moved backward and forward by the pressure of steam. The kinetic energy of a movable piston can be employed to rotate the wheels of a automobile, a turbine, or any other machine based device.

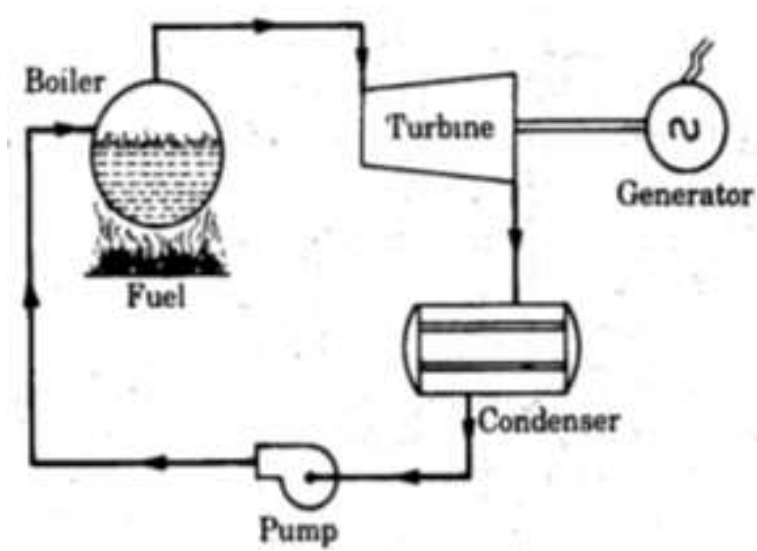

Figure 3 Diagram of External Combustion Engine

Internal Combustion engine - Fuel is burned internally, or within the engine, in any engine then it is said to be an internal combustion engine. One such kind of engine can be found in a wide range of automobiles, not just cars. The engine operates in a sequence of processes that repeat themselves.A valve pulls a combination of fuel and air together into cylinder, which further shuts down. The fuel-air combination in the shuttered cylinder is compressed by a piston moving upward within the cylinder. The combination is now extremely hot and under a massive pressure. The fuelair combination is ignited by a spark out of a spark plug, allowing it to combust explosively inside the enclosed area of the covered cylinder. The piston is pushed downside by the pressure of the vapors produced by combustion. The piston rises once more, forcing exhaust gases out from the cylinder via a different valve. The piston descends once more, as well as the cycle begins repeatedly.

Once heat is introduced to the device, the gas inside it starts expanding. This elevates the piston inside a piston engine; in a turbine, high temperature air is pushed into the turbine compartment, causing the turbine to spin as shown in (Figure 4). The engine can transform some amount of the energy provided to the frame into productive task by allocating either cylinder or turbine towards a camshaft. [2] The gas is displaced by the engine in order to cover the bottle into a batch combustion engine (BCE). After that, a conductor is utilized to maintain the scaffold at a fixed temperature. A ongoing combustion turbine eliminates gas continuously rather than in cycles. 


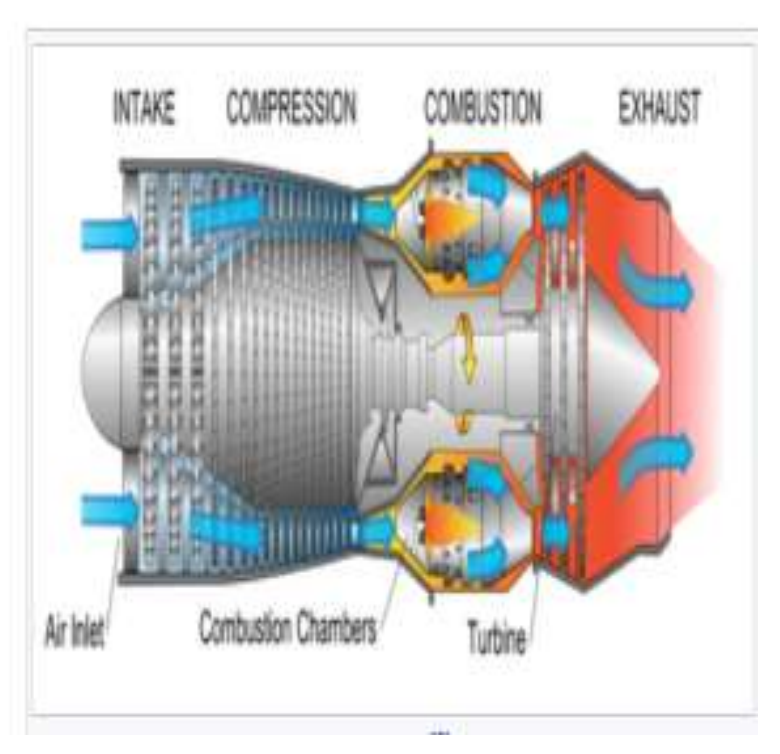

Figure 4 Diagram of Gas Turbine Engine

Times over the past decade, there has already been a growing interest in applying control theory to automobiles which carry people or goods, as government regulations limiting fuel usage and exhaust emissions have necessitated the use of interconnected electronics control system. Regrettably, the absence of adequate global models for the evolution of the IC engine has restricted the use of control theory techniques in this field.

\section{LITERATURE REVIEW}

J. Laxmi Prasad et al. [1] The ribs are an important component of an internal combustion engine's square compartment, which causes heat distribution throughout the contact of the ignition by deportation or convection. The heat end's constructive motion can surely keep up including an internal ignition engine's fixed efficiency. The plates come in a variety of shapes and sizes, with the majority of them being used depending on the speed upon which thermal stirring is required. The main goal of the project is to use heat to deconstruct characteristics by varying the arithmetic and the width of the vanes in the chamber.

Lei Li et al. [2] Some other type of dual central turbine circular pattern including wavy ribs in the internal cavity was invented to additionally establish the convective heating movement of the turbine disc with high tension. A computerized methodology that has been authenticated employing a empty plate model decomposes the convective heat movement characteristics of conventional TWD and TWD including fins.

NgoctanTranet et al. [3] Four drawbacks are quantitatively investigated in this assessment in order to maximize heat advancement on the air side of a flat cylinder heating element, which include blade varieties, compensation pitch, compensation width, and fin tip. Emerging testing outcomes are utilized to substantiate the present numerical approach, with the broadest variances for heat motion speed and outlet or exit temperature being less than $1.65 \%$ and 0.27 percent, respectively.

Adeel Tariq et al. [4] Using a molded thermal motion model and other research, the advantages of experiencing numerous holes and entrances in a finned heat sink are investigated. The two inventive ribbed radiators are used to investigate heat transfer and diversification waste (with openings and engravings). The test findings prove the air-cooled heat sink's CFD-shaped heat movement trend. According to the outcome of the CFD model, the different versions of finned heat sinks have a higher coefficient of heat movement than flat blades including holes or excluding holes.

The usage of permeable flakes can enhance heat mobility in the plates, according to PulkitSagar et al. [5]. The contraction of the heat moving speed demonstrates the efficiency of the force provided and improves the engine's effectiveness. The main goal of this research is to slow down the rate of heat motion by distinguishing among ground fatigue and internal fatigue (250 micrometers, 300 micrometers and 400 micrometers). The rate of motion of heat is monitored by employing a warm experiment for different surface inconveniences. The rate of motion of body heat was studied using a parametric model.

Ling dong Gu et al.[6] The heating characteristics of water on the air side of heat transfer systems which includes exposed duct system and unwrinkled finned pipes for refrigerating aircraft engines were investigated using computational equations. The heat exchangers work at high temperatures with large temperature fluctuations all across the depth of the heat exchanger and have a short distance in between pipes $(3.0 \mathrm{~mm})$ with a surface area of the lower cylinder. Frontal air velocities of 5 to $20 \mathrm{~m} / \mathrm{s}$ are estimated, resulting in Reynolds numbers (Re) for pipe widths ranging from 4898 to 19,592 .

KummithaObula Reddy et al. [7] The chamber component of internal ignition engines is the engine's soul, and this compartment component formation the separating facades of a combustion chamber where the air-fuel mixture is consumed. The combustion region of the compartment splitters and the motion of heat through the chamber material are the result of this consistent measurement of ignition. The rate of temperature discharge from the chamber is a main and fascinating worry because if the hot air is not dispersed as predicted, it will cause destruction and, in the longterm, mitigate engine fuel economy. In most case scenarios, the speed at which heat moves throughout a material is measured by its heat capacity.

Akash M Vyas et al. [8] Heat is produced when fuel is combusted in an engine. The interactions among the movable components generates supplementary heat. Approximately $30 \%$ of the radiation emitted is transformed 
into productive tasks; the remaining $70 \%$ should be handed back to the air conditioning unit by the engine to dissipate excessive heating the components. To boost up the rate of heating motion in an inside firing air-cooled engine, extended areas named blades are offered all around perimeter of the engine chamber. Dismantle the magnitude in a structured manner to determine the rate of heat motion.

Divyank Dubey and colleagues [9] By varying the width of the motor fin tip to almost $3 \mathrm{~mm}$ and offering entry points of $50 \mathrm{~mm}, 75 \mathrm{~mm}$, and $100 \mathrm{~mm}$ of a related plane on Solidworks software and surveys on ANSYS - Steady state, researchers wish to expand the effect on heat dispersion on such expanded interfaces in this editorial. To make comparisons of the achievement of this research study to previous results, researchers will employ the Bajaj measure. They evaluate the visibility and varying outcomes employing various materials with higher thermal conductivity, such as 6061 aluminum compound, C443 aluminum composite, and 2014 aluminum amalgam.

Hongda Liu et al. [10] A mathematical analysis of the finned tube exchanger of an ORC structure for recovering residual heat from a diesel engine is created in this proposed plan. For multi-target refinement of the finned tube exchanger, the Particle Swarm Optimization (PSO) computation is used. Important mathematical boundary lines are preferred as choice limits, such as tubing side passage sweep, shell side segment span, blade stature, adjustment width, and balance splitting.

\section{COMBUStion-ENGINE CHALLENGES}

Since the 19th century, the internal combustion engine has revolutionized transport services. Nowadays, thereare more than one billion vehicles on the road in the entire planet, with approx. 95 million produced each year, the overwhelming bulk of which are powered by a combustion engine. The combined effect of simplification, longevity, low wattage ratio, high power stability, and satisfactory effectiveness is the justification for its enduring popularity. Engine scientific research is primarily intended to reduce emissions and lowering fuel usage, as mandated by legislative changes. This is due to localized harmful emissions, as well as the reality that the transport industry accounts for $23 \%$ of greenhouse gas emissions globally.

$\mathrm{CO}$, incomplete combustion hydrocarbons (HC), and particle quantity emissions are all controlled. Benchmarks for greenhouse-gas emissions standards are presumed to be included in upcoming regulations. Choices to internal combustion engines such as battery-electric and fuel-cell vehicles are possible zero-emission options. But even so, given the sheer number of combustion engines currently on our roadways, mass manufacturing will almost undoubtedly keep over many years, particularly in the massive duty sector.
In this situation, new technologies in combustion engines, combined with hybridization and biofuel use, could provide a cost-effective route to lower local and global emission levels. High-pressure fuel implantation, exhaust gas recirculation (EGR), and compaction and refrigeration of instated air are examples of engine technology advancements for relatively clean combustion. In order to comply with existing legislation, combustion filters and catalysts are also required. As a result of the increased engine difficulty, the quantity of sensors and actuators has increased, allowing for the development of more advanced engine-control processes.

The implementation of novel, clean, and effective combustion concepts has also been prioritized. An amount of these concepts rely on increased fuel and air blending in the combustion chamber to achieve low temperature combustion with low emission formation and heat transfer speeds. The subsequent sections provide a brief review of basic engine precepts and contrast traditional diesel combustion with low temperature combustion.

\section{CONVENTIONAL DiESEL ENGINES}

Quite some time, the usage of free pistons in internal combustion engines (ICE) has been explored. Experimental studies with free piston engines in vehicle industries were carried out in the 1950s. The engine was being used as a gasification process for a solitary stage turbine in these early models. Hydraulic pumps have been incorporated into the engine technology in much more current revelations. There are a number of advantages to free piston IC engines. Initially, the engine's compression ratio is changeable; it is primarily determined by the engine's operational conditions (e.g., fuel type, equivalence ratio, temperature, etc.). As a result, rather than changing the engine's equipment, the requested compression ratio can be achieved by adjusting the operational characteristics.

High-pressure fuel infusion into a compact, hot (1000 K) air charge near to TDC initiates conventional diesel combustion. Infused fuel spreads throughout the combustion chamber, forming a cone - shaped jet of fuel spray. As the fuel jet expands, it becomes increasingly diluted with hot air and vaporizes. The fuel has completely vaporized after some distance along the jet axis (about 20-25 mm), known as the lift-off length. After more entrapped air, chemical reactions begin all over the jet cross section. Due to an excess of fuel, the initial reactions are accompanied by quick, rich, fuel blends, and the eventually results warming trend leads to the creation of soot.

Because once molar ratio situations are attained, entrapped air persists as the responding fuel moves or along spray axis, forming a quasi-steady diffusion flame along the jet periphery. The rate at which the injected fuel is vaporized, mixed with air, and supplied to the diffusion flame controls the combustion rate at this stage. As a result, this sort of 
combustion is alluded to as combining controlled combustion. The temperature rises to its highest point near the flame, causing nitrogen to oxidize and emit harmful NOx. Soot oxidation occurs when a high temperature is combined with the access to oxygen, resulting in the characteristic diesel-flame luminosity.

\section{ENGINE PERFORMANCE OF THE BIODIESEL FROM PLANTS OIL}

The ICE is an engine wherein a propellant (usually a fossil fuel, but now also a biofuel) is burned in a combustion process that is part of the working fluid flow loop with an oxidizing agent (usually air). The expansion of the hightemperature and high-pressure gases produced by combustors acts directly on certain engine parts in an Internal Combustion Engine (ICE). Usually, the force must be applied to pistons. The element is moved over a distance by this force, which converts chemical energy into beneficial mechanical power.

The transformation of chemical energy to mechanical energy aids in the determination of various specifications including engine performance, brake thermal effectiveness, brakespecific fuel usage, and brake power; measuring all of these yields an engine's effectiveness. As a result, the performance of an engine using various biofuels will help determine how widely biofuels will be used as alternative fuels.

In compression ignition (CI) engines, oil from vegetable seeds can be used as fuel without any modifications. Nonedible oils have been shown to be a good alternative fuel in research findings. Smoothing biodiesel is an interim way to solve problems of limited supply and emissions without modifying engine technology. Experiments have shown that when non-edible biodiesel is blended with diesel at a rate of $10 \%$ to $20 \%$, performance of the engine is comparable to that of engines running on conventional diesel. To examine the performance of engines, experiments were conducted on a four-stroke, four-cylinder indirect injection water-cooled CI engine. B20 was used as a fuel.

At fixed speed of 1500 RPM, the load was ranged from no load to a peak value of $12 \mathrm{~kW}$. The thermal efficiency of the biodiesel blend was discovered to be higher than that of diesel. B20 had an elevated FP, which improved storage and handling safety. An engine was used to test the performance of karanj oil (K100) and karanj oil combined with diesel fuel (K10, K15, or K20). Specific fuel consumption rises as the blend level rises, but K15 has the lowest brake-specific fuel usage due to its diesel-like characteristics.

The impact of neem oil and its methyl ester on a solitary cylinder, straight-forward, four-stroke diesel engine demonstrates that over full load, the peak in - cylinder pressure is significantly greater, but the maximum heat release rate throughout the prior mixed combustion phase is lesser. Once compared to diesel at full load, ignition lag for clean neem oil and neem oil methyl ester is shorter in this situation. The duration of combustion is longer, but the thermal efficiency of the brakes is marginally lower.

\section{CLASSIFICATION OF IGNITION ENGINES}

Depending on the type of ignition (according to method of ignition)

SI engine (A): A spark-ignition engine (SI engine) is an internal combustion engine (IC engine) that uses a spark plug to initiate the combustion loop of an air-fuel combination.

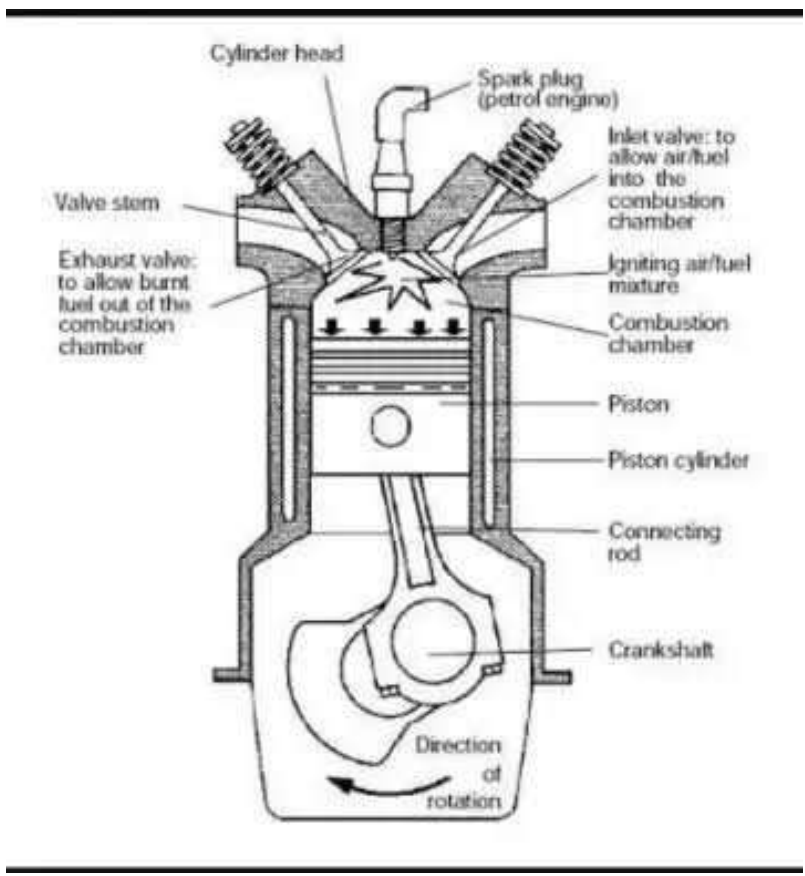

B) CI engine: A CI engine is a category of internal combustion engine (ICE) that uses the heat of compaction to ignite the fuel charge.

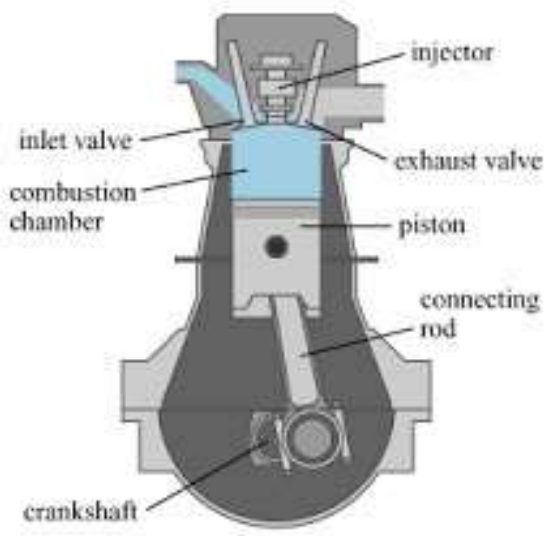

Depending on the types of fuel used

A) petrol based engine; -A petrol engine (British English) or gasoline engine is a spark-ignition internal combustion engine that runs on gasoline (gasoline) as well as other combustible fuels. 


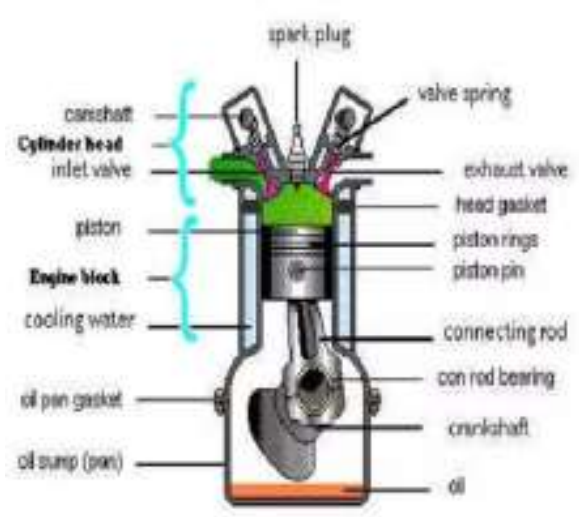

B) Diesel based engine: A diesel engine (also known as a compression-ignition or CI engine) is an ICE labelled after Rudolf Diesel wherein the fuel is ignited by the elevated temperature of the air in the cylinder caused by mechanical compaction (adiabatic compression).

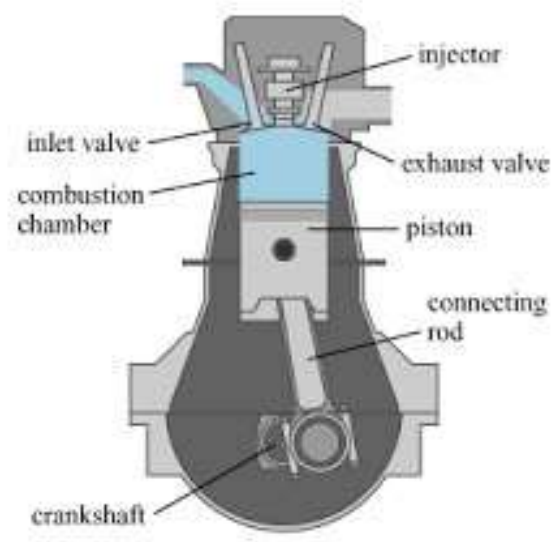

C) Gas engine: A gas engine is type of internal combustion engine that uses a gaseous fuel including coal gas, producer gas, biogas, landfill gas, or natural gas as its fuel

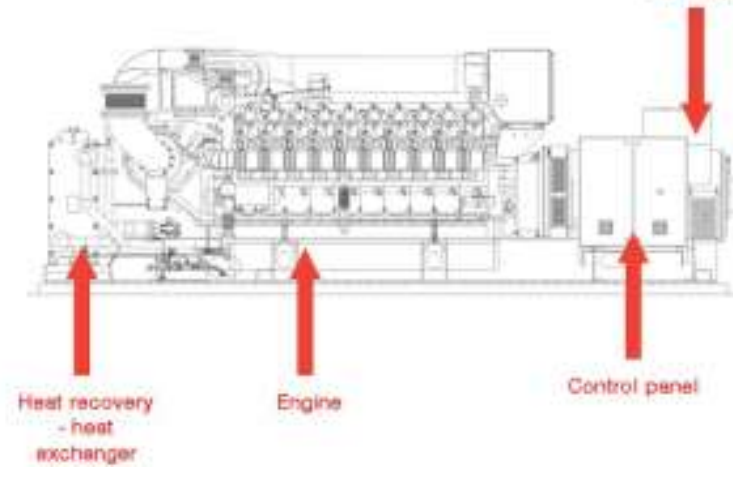

The quantity of strokes for every cycle (as per the processing cycle is used to classify IC engines.
Engine with two strokes: -

A two-stroke (or two-cycle) engine is an internal combustion engine that performs a two-stroke (up and down) power cycle of the piston in a solitary crankshaft rotatory cycle.

Engine with fourstrokes: -

The four-stroke (also known as four-cycle) engine is an internal combustion (IC) engine wherein the piston accomplishes 4 different strokes whereas the crankshaft is rotated.

We have such a world - class infrastructure that is based on internal combustion, and renewable alternative solutions are simply not feasible for such forms of transportation. Container ships, cruise liners, and heavy vehicles are all examples of heavy vehicles. Nonetheless, it is in these categories that among the worst environmental damage occurs.

\section{WORKING PROCESS OF INTERNAL COMBUSTION ENGINE}

Internal combustion engines are used in the overwhelming bulk of vehicles sold today (both passenger cars and commercial vehicles).

A heat engine is a type of internal combustion engine. It's called internal because the air-fuel combination is combusted in a combustion process within the engine, and that some of the destroyed gases are reused in the innovative combustion stroke.Internal combustion engines rely on the exothermic chemical burning process, which involves the reaction of a fuel with air, while other oxidizers including such nitrous oxide may also be used. The most widely accepted fuels in use nowadays are hydrocarbons, which are almost always made from petroleum. Diesel fuel, gasoline, and petroleum gas, as well as propane gas, are examples of these. Excluding the fuel supply elements, often these internal combustion engines intended for gasoline can operate on natural gas or liquefied petroleum gases without significant revisions. Ethanol and biodiesel, a type of diesel fuel made from crops that generate triglycerides like soy bean oil, are examples of liquid and gaseous biofuels that can be used. Many are also capable of running on hydrogen gas.

The way gasoline engines delivers and ignite fuel differs from how compression ignition diesel engines do. Throughout. the inlet process of a spark ignition engine, the fuel is combined with air and then inducted 
into the cylinder. The spark ignites the fuel-air combination after the piston shrinks it, starting to cause burning. Although during power stroke, the fumes expand and push the piston. Only air is inducted into a diesel engine, which is then squeezed. Diesel engines then splash the fuel through into hot compressed air at a controlled rate, igniting it.

\section{CONCLUSION}

Transportation is compelled in some form or another all over the world to experience the most basic needs. The combustion engine is no longer visible from this moment forward. A range of different of fuels are required to keep a machine running. Out from perspective of history, people all over the world have been continuing to work on the Internal Combustion (IC) engine, its processes, and its advancement. The main focus in recent times has been on increasing fuel economy and lowering emissions. Researchers have discovered no alternative type that offers significant fuel economy or controlled emission benefits, and none that compares to today's engines in terms of overall ease, protection, and adaptability.

Thus in this paper we have discussed about the combustion engines and its types, working and also the work done by numerous of researchers to enhance the efficiency of heat exchangers in combustion engines with different geometry.

\section{REFERENCES}

[1] J. Laxmi Prasad, NEC Prasad, Bugudala Srinivas "Heat transfer analysis for two-wheeler engine cooling fins by using CFD", AIP Conference Proceedings 2317, 030015 (2021); https://doi.org/10.1063/5.0036340.

[2] LeiLi, ZhonghaoTang, HonglinLi, "Convective heat transfer characteristics of twin-web turbine disk with pin fins in the inner cavity", International Journal of Thermal Sciences Volume 152, June 2020, 106303.

[3] Ngoctan Tran, Chi-ChuanWang, "Optimization of the airside thermal performance of mini-channel-flat-tube radiators by using composite straight-and- louvered fins", International Journal of Heat and Mass Transfer Volume 160, October 2020, 120163.

[4] Adeel Tariq, KhurramAltaf "Comparative Numerical and Experimental Analysis of Thermal and Hydraulic Performance of Improved Plate Fin Heat Sinks", Applied Thermal Engineering Available online 26 August 2020, 115949.
[5] PulkitSagar, PuneetTeotiaAkash Deep Sahlot "Heat transfer analysis and optimization of engine fins of varying surface https://doi.org/10.1016/j.matpr.2017.07.203. roughness",

[6] Ling dong Gu, Jingchun Min, Xiaomin Wu "Airside heat transfer and pressure loss characteristics of bare and finned tube heat exchangers used for aero engine cooling considering variable air properties", International Journal of Heat and Mass Transfer Volume 108, Part B, May 2017, Pages 1839-1849

[7] KummithaObulaReddy, B.V.R.Reddy, "Thermal Analysis of cylinder block with fins for different materials using ANSYS", Materials today: proceedings 4(8):81428148.

[8] Akash M Vyas, Ruchir Parikh, Dr. UmangPatdiwala "Analysis of I.C. Engine Fins for Effective Cooling Performance", IJSTE - International Journal of Science Technology \& Engineering | Volume 5 | Issue 1 | July 2018.

[9] Divyank Dubey, Dinesh Singh, AbhishekyadavSatyajeet pal, "Thermal Analysis of Engine Cylinder having thick tip fin with varying slot sizes and material",2017 .

[10] Hongda Liu Hongguang Zhang et al, "Multiobjective optimization of fin-and-tube evaporator for a diesel engine-organic Rankine cycle (ORC) combined system using particle swarm optimization algorithm", Energy Conversion and Management Volume 151, 1 November 2017, Pages 147157.

[11] Su Min Hoi, An Liang Teh, "Plate-fin heat sink forced convective heat transfer augmentation with a fractal insert", International Journal of Thermal Sciences Volume 142, August 2019, Pages 392-406

[12] A Sathishkumar, MD KathirKaman, S Ponsankar "Design and thermal analysis on engine cylinder fins by modifying its material and geometry", Journal of Chemical and Pharmaceutical Sciences, Vol 4, pp 43-49, 2015.

[13] S.S.Chandrakant, ShindeSunilkumar "Numerical and Experimental Analysis of Heat Transfer through Various Types of Fin Profiles by Forced Convection." International Journal of Engineering Research \& Technology (IJERT) 2(7), 2013.

[14] N.P.R. Rao and T. V. Vardhan. "Thermal Analysis of Engine Cylinder Fins By Varying Its Geometry and Material." International Journal of Engineering 2(8), 2013.

[15] A.R. Kumar, G. Janardhana Raju (2013). "Heat Transfer Analysis in the Cylinder Head of a Four-Stroke Si Engine." International Journal of Engineering Research \& Technology (IJERT) 2(5), 2013. 
[16] S. Barhatte, M. R. Chopade. "Experimental and Computational Analysis and Optimization for Heat Transfer through Fins with Different Types of Notch." Journal of Engineering Research and Studies E-ISSN 976: 7916, 2011.

[17] P. Agarwal, MayurShrikhande, P. Srinivasan "Heat Transfer Simulation by CFD from Fins of an Air Cooled Motorcycle Engine under Varying Climatic Conditions". Proceedings of the World Congress on Engineering, 2011.

[18] U. Magarajan, RajR. Thundilkaruppa, T. Elango "Numerical Study on Heat Transfer of Internal Combustion Engine Cooling by Extended Fins Using CFD." International Science Congress Association 1(6): 32-37, 2012.

[19] G. Raju, BhramaraPanitapu, S. C. V. RamanaMurty Naidu "Optimal Design of an I.C. Engine Cylinder Fin Arrays Using a Binary Coded Genetic Algorithms." IJMER, 2(6): 4516-4520, 2012.

[20] M. Matkar and P. M. Ravanan "Thermal Analysis of Copper Fin by FEA”. International Conference on Operations and Quantitative Management. Nasik, India, 2011. 